
Natural Killer Cell Immunological Synapse

Leo M. Carlin, Rachel Evans, Hanna Milewicz, Luis Fernandes, Daniel R.

Matthews, Michela Perani, James Levitt, Melanie D. Keppler, James Monypenny, Ton Coolen, Paul R. Barber, Borivoj Vojnovic, Klaus Suhling, Franca Fraternali, Simon Ameer-Beg, Peter J. Parker, N. Shaun B. Thomas and Tony Ng (29 November 2011)

Science Signaling 4 (201), ra81. [DOI: 10.1126/scisignal.2001729]

The following resources related to this article are available online at http://stke.sciencemag.org. This information is current as of 30 November 2011.

Article Tools Visit the online version of this article to access the personalization and article tools: http://stke.sciencemag.org/cgi/content/full/sigtrans;4/201/ra81

\section{Supplemental} Materials

\section{References}

Glossary

Permissions
"Supplementary Materials"

http://stke.sciencemag.org/cgi/content/full/sigtrans;4/201/ra81/DC1

This article cites 74 articles, 42 of which can be accessed for free:

http://stke.sciencemag.org/cgi/content/full/sigtrans;4/201/ra81\#otherarticles

$$
\text { Look up definitions for abbreviations and terms found in this article: }
$$$$
\text { http://stke.sciencemag.org/glossary/ }
$$

Obtain information about reproducing this article:

http://www.sciencemag.org/about/permissions.dtl 


\title{
A Targeted siRNA Screen Identifies Regulators of Cdc42 Activity at the Natural Killer Cell Immunological Synapse
}

\author{
Leo M. Carlin, ${ }^{1,2 \star \dagger \ddagger}$ Rachel Evans, ${ }^{1,2 \star}$ Hanna Milewicz, ${ }^{3}$ Luis Fernandes, ${ }^{2}$ \\ Daniel R. Matthews, ${ }^{1,2,4}$ Michela Perani, ${ }^{4}$ James Levitt, ${ }^{5}$ Melanie D. Keppler, ${ }^{1,2}$ \\ James Monypenny, ${ }^{1,2,6}$ Ton Coolen, ${ }^{2,7}$ Paul R. Barber, ${ }^{2,8}$ Borivoj Vojnovic, ${ }^{2,8}$ Klaus Suhling, ${ }^{5}$ \\ Franca Fraternali, ${ }^{2}$ Simon Ameer-Beg, ${ }^{1,2,4}$ Peter J. Parker, ${ }^{4,9}$ N. Shaun B. Thomas, ${ }^{3}$ Tony Ng ${ }^{1,2,4,6 \neq}$
}

\begin{abstract}
Natural killer (NK) cells kill tumor cells and virally infected cells, and an effective NK cell response requires processes, such as motility, recognition, and directional secretion, that rely on cytoskeletal rearrangement. The Rho guanosine triphosphatase (GTPase) Cdc42 coordinates cytoskeletal reorganization downstream of many receptors. The Rho-related GTPase from plants 1 (ROP1) exhibits oscillatory activation behavior at the apical plasma membrane of growing pollen tubes; however, a similar oscillation in Rho GTPase activity has so far not been demonstrated in mammalian cells. We hypothesized that oscillations in Cdc42 activity might occur within NK cells as they interact with target cells. Through fluorescence lifetime imaging of a Cdc42 biosensor, we observed that in live NK cells forming immunological synapses with target cells, Cdc42 activity oscillated after exhibiting an initial increase. We used protein-protein interaction networks and structural databases to identify candidate proteins that controlled Cdc42 activity, leading to the design of a targeted short interfering RNA screen. The guanine nucleotide exchange factors RhoGEF6 and RhoGEF7 were necessary for Cdc42 activation within the NK cell immunological synapse. In addition, the kinase Akt and the p85a subunit of phosphoinositide 3-kinase (PI3K) were required for Cdc42 activation, the periodicity of the oscillation in Cdc42 activity, and the subsequent polarization of cytotoxic vesicles toward target cells. Given that PI3Ks are targets of tumor therapies, our findings suggest the need to monitor innate immune function during the course of targeted therapy against these enzymes.
\end{abstract}

\section{INTRODUCTION}

The Rho family of small guanosine triphosphatases (GTPases), which includes RhoA, Cdc42, and Rac, contains important regulators of actin-dependent processes, such as vesicular trafficking and the formation of membrane protrusions during cell motility (1). We and others have monitored changes in the activities of Förster resonance energy transfer (FRET) sensors in various cell systems that were challenged by different extracellular signals and showed the precise spatiotemporal correlation between Rho GTPase activation and membrane-protrusive events that are associated with cell motility (2-11). Although the oscillatory activation of ROP1, a Rho-like GTPase in plants, at the apical plasma membrane of growing pollen tubes has been demonstrated (12), a similar oscillation in the activity of a mammalian Rho

${ }^{1}$ Richard Dimbleby Department of Cancer Research, King's College London, London SE1 1UL, UK. 'Randall Division of Cellular and Molecular Biophysics, King's College London, London SE1 1UL, UK. ${ }^{3}$ Cell Cycle and Epigenetics Laboratory, Department of Haematological Medicine, The Rayne Institute, King's College London, London SE5 9NU, UK. ${ }^{4}$ Division of Cancer Studies, King's College London, London SE1 1UL, UK. ${ }^{5}$ Department of Physics, King's College London, London WC2R 2LS, UK. ${ }^{6}$ Breakthrough Breast Cancer Research Unit, Research Oncology, King's College London, Guy's Medical School Campus, London SE1 1UL, UK. 'Department of Mathematics, King's College London, London WC2R 2LS, UK. ${ }^{8}$ Gray Institute for Radiation Oncology and Biology, University of Oxford, Old Road Campus Research Building, Roosevelt Drive, Oxford OX3 7DQ, UK. ' $\mathrm{C}$ ancer Research UK London Research Institute, Lincoln's Inn Fields, London WC2A 3LY, UK.

*These authors contributed equally to this work.

†Present address: Centre for Molecular and Cellular Biology of Inflammation, King's College London, London SE1 1UL, UK.

‡To whom correspondence should be addressed. E-mail: leo.carlin@kcl.ac. uk (L.M.C.); tony.ng@kcl.ac.uk (T.N.)
GTPase has not been shown with these sensor techniques. We postulated that such dynamic changes may be more easily discerned within cells of the immune system that maintain an active surveillance process that occurs during cell-cell interactions and is dependent on the actin machinery.

Natural killer (NK) cells are large granular leukocytes that play an important role in defense against viruses and tumors (13). NK cells do not exhibit antigen specificity in the same sense as do T and B cells; rather, they integrate a number of positive and negative signals to determine whether to kill a suspect cell. NK cells exhibit exquisite control when surveying potential target cells for disease. Many of these signals emanate from membrane-bound receptors, such as adhesion and cytokine receptors. Signals from these receptors are integrated to influence the formation of conjugates of NK cells and target cells that contain dynamic structures at the cell-cell interface, which is termed the immunological synapse (14-16), through regulators of the actin cytoskeleton, such as Wiskott-Aldrich syndrome protein (WASP) (17). However, a central gap in our knowledge about the NK cell immunological synapse is how these signals are integrated in time and space to determine the eventual outcome of the interaction (18).

Oscillatory cell movement in the form of "waves" of spreading and contraction has been shown in live NK cells responding to antibodyinduced ligation of surface NKG2D receptors, which contribute to the formation of NK cell-target cell conjugates and subsequent killing (19). The mechanisms for these temporal changes in membrane movement are poorly understood but are likely to relate to the intermittent accumulation of polymerized actin at the tentative NK cell-target cell interface, as described previously (20). The process of NK cell-target cell conjugation therefore constitutes an ideal cell biological system to search for oscillations of Rho GTPase activity during cell-cell interactions. 
In the context of immunological synapses, the generation of sensory contact domains involves the formation of actin-based protrusions (21), such as filopodia, which are dependent on the function of the Rho GTPase $\mathrm{Cdc} 42$. Cdc42 is implicated in regulating changes in cell morphology and motility as well as vesicular transport; thus, $\mathrm{Cdc} 42$ is a good candidate for integrating both positive and negative signals from cell surface receptors to achieve the morphological changes essential for immune surveillance and cytotoxicity (22-25). Cdc42 activity in cells can be imaged effectively with the FRET biosensor Raichu-Cdc42, which changes conformation in response to $\mathrm{Cdc} 42$ guanine nucleotide exchange factor (GEF) activation, bringing two fluorescent proteins into closer proximity so that FRET occurs (fig. S1A) $(2,26,27)$. We modified this sensor to express monomeric red fluorescent protein (mRFP) and enhanced green fluorescent protein (eGFP) to make it suitable for quantitative FRET by fluorescence lifetime imaging microscopy (FLIM), which is generally considered the gold standard for FRET-based detection of protein-protein interactions (28). We refer to this modified method as Raichu-FLIM $(5-10,29)$. Here, we quantified the $\mathrm{Cdc} 42$ activity in a model system of immune surveillance by human NK cells and demonstrated that Cdc42 activity oscillated with a periodicity of 300 to $350 \mathrm{~s}$ in NK cells that interacted with potential target cells. We designed a Raichu-FLIM screen based on the Cdc42-centered protein subnetwork (30) and showed that Cdc42 activity in NK cells was reduced to a basal extent by short interfering RNAs (siRNAs) specific for the known GEFs for Cdc42 ( $\alpha$-PIX and $\beta$-PIX) when they were knocked down in concert. In addition, siRNAs against the p85 $\alpha$ subunit of phosphoinositide 3-kinase (PI3K) and Akt as well as a PI3K inhibitor abrogated Cdc42 activity and modified the periodicity of its oscillation. Both p85 $\alpha$ - and Akt-specific siRNAs also disturbed the polarization of cytotoxic granules toward target cells by interfering with Cdc42-dependent vesicular transport. Thus, this combination of bioinformatic target identification and functional imaging has increased our understanding of the functional hierarchy of the Cdc42 signaling network in NK cells. Because PI3Ks are targeted by therapies against tumors, our findings suggest that NK cell immune function should be monitored during the course of targeted therapy against this class of enzymes.

\section{RESULTS}

\section{Cdc42 activity first increases and then oscillates during NK cell-target cell interactions}

We used multiphoton FLIM to visualize Raichu-Cdc42 activity in YTS NK cells upon their interaction with potentially activating 721.221 target cells. After detecting an initial increase in the activity of $\mathrm{Cdc} 42$, we found that the mean Cdc42 activity oscillated with time during NK cell-target cell interactions, whereas such behavior did not occur in NK cells imaged alone (Fig. 1, A and B, and movie S1). High, localized Cdc42 activity was observed at the NK cell-target cell interfaces of the first conjugate (Fig. 1, $\mathrm{A}$ and $\mathrm{B}$, left). In the second example of an NK cell-target cell conjugate (Fig. 1, A and B, conjugate 2), active Cdc42 was homogeneously distributed across one cell-cell interface (IS \#2), whereas at both immunological synapses in the first conjugate (Fig. 1, A and B, left) and in the other immunological synapse of the second conjugate (IS \#1), the Cdc42 activity was more heterogeneous. This heterogeneous activity was reminiscent of images of microclusters containing phosphorylated killer cell immunoglobulinlike receptor (KIR) and the adaptor protein Lck that were previously observed at the inhibitory immunological synapse of NK cells (31). When our analysis was performed at the level of each individual immunological synapse rather than at the level of the whole cell (Fig. 1A, IS \#1 and IS \#2), we found that the oscillation in $\mathrm{Cdc} 42$ activity was still apparent with a consistent periodicity, except for IS \#2 of the second conjugate in which there was an initial increase in FRET efficiency (to $>30 \%$ ), which then became stabilized and did not oscillate. The stable area of activity did not come from saturation of the color scaling, but most likely represented a maximal and sustained $\mathrm{Cdc} 42$ activation at the synapse site, as could be seen when this individual immunological synapse was analyzed (Fig. 1A, IS \#2 of conjugate 2). By an approach similar to that used to calculate contractile periodicity in T cells (32), we used a discrete Fourier transform method of power spectrum analysis to calculate the periodicity of the oscillation in Cdc42 activity for entire NK cells and for the individual immunological synapses. The periodicity of the individual immunological synapses was consistent with the dominant period of oscillation in $\mathrm{Cdc} 42$ activity for the whole cell-cell conjugate. The periodicity of Raichu-Cdc42 activity for a number of representative interactions between NK cells and target cells was calculated as above, and we observed that the dominant periodicity for all of the oscillations was 300 to 375 s (Fig. 1C). In contrast, the amplitude of any oscillation in the signal in NK cells alone was minor (Fig. 1, A and B, far right). We ruled out oscillatory noise from the imaging technique itself as the cause of our observations, because when we measured the fluorescence lifetime of Cdc42-GFP alone in unconjugated NK cells under the same conditions, we found that the average lifetime did not change or oscillate over time (fig. S1B).

\section{A Cdc42 interaction subnetwork predicts siRNA targets with a functional role in NK cell-target cell interactions}

An increasing number of studies have integrated the results of large-scale RNA interference (RNAi) screens with protein-protein interaction data as an efficient means to uncover the biological relevance of the identified candidates. Although such approaches have proven reliable, they rely on largescale studies that require a substantial amount of resources. The integration of interaction network data within the experimental design can substantially reduce these demanding needs. $\mathrm{Cdc} 42$ is potentially regulated by a large number of upstream and downstream signaling molecules that could affect immune surveillance by NK cells. We took a bioinformatics approach to identify potential regulators of $\mathrm{Cdc} 42$ that were also $\mathrm{Cdc} 42$-interacting proteins, and we then investigated the effects of these potential regulatory elements within the subnetwork through a focused Raichu-FLIM screen performed in combination with RNAi-mediated knockdown of potential candidates, as described previously (30).

We mined the Human Protein Reference Database (HPRD, http:// www.hprd.org) (33) for proteins that interact with Cdc42. To effectively take into account the regulators of $\mathrm{Cdc} 42$, we then applied a filter based only on proteins that interacted directly with $\mathrm{Cdc} 42$, as well as on the interactions among these proteins themselves. Each protein in the network was annotated with information regarding its domain architecture, as described in the PFAM (protein families) database (http://pfam.sanger.ac.uk/) (34). Protein-protein interactions can be characterized by the underlying domain-domain interactions, as cataloged in the publicly available database $i$ PFAM (http://ipfam.sanger.ac.uk/). The interactions reported in $i$ PFAM are derived from the assignment of PFAM domains to the threedimensional structures of protein complexes. We embedded $i$ PFAM data into the network to assign the reported interactions a degree of confidence; that is, if two proteins that were reported to interact with each other were composed of domains that should interact according to $i$ PFAM, then we assigned that specific link a higher confidence than was assigned to those proteins that did not contain interacting domains in the network. The contrary was assumed (low confidence) when no interacting domains in $i$ PFAM were detected for the given proteins (fig. S2B).

We assembled data from these three sources (HPRD, PFAM, and $i$ PFAM) and obtained a subnetwork of $\mathrm{Cdc} 42$ regulators (fig. S2A). We 
A
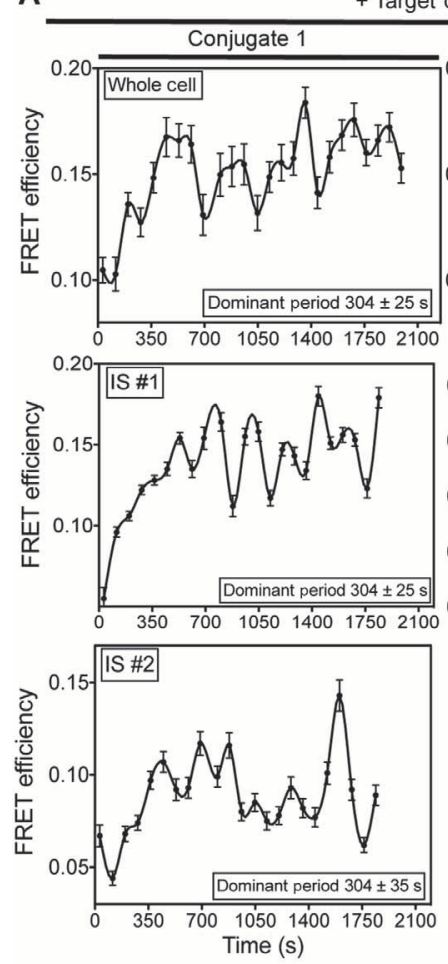

B
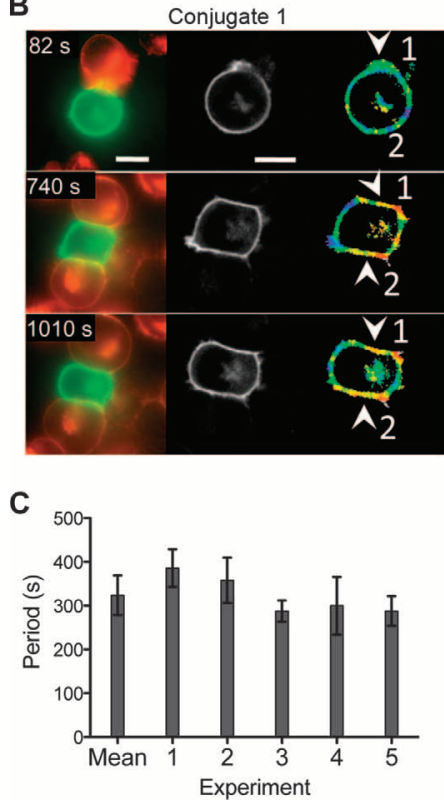
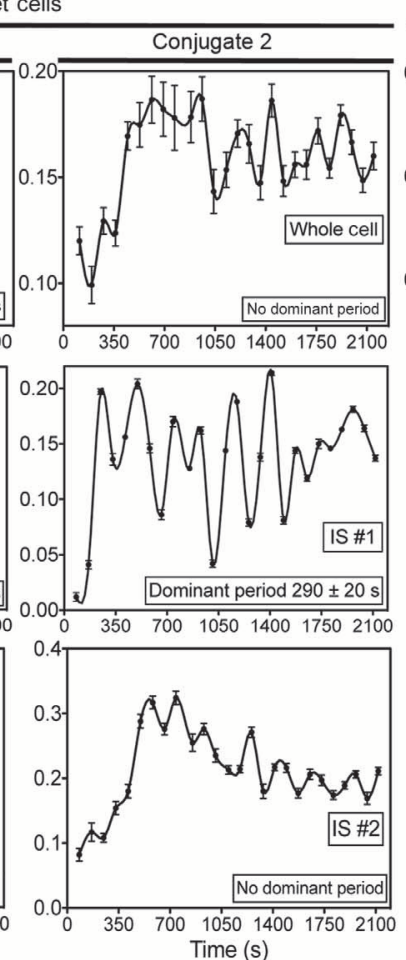

Conjugate 2
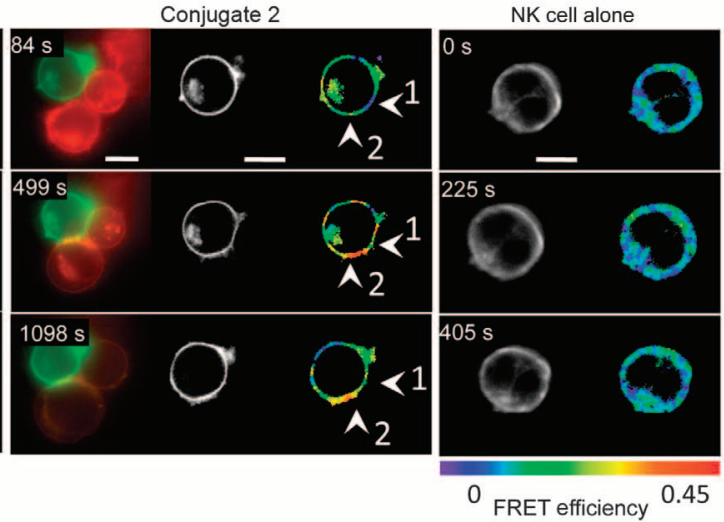

Fig. 1. Cdc42 activity increases and oscillates during NK cell-target cell interactions. ( $A$ and $B$ ) Plots of the mean FRET efficiency over time from time-lapse FLIM analysis of two conjugates of a Raichu-Cdc42expressing YTS NK cell and 721.221 target cells (+ Target cells) and of a Raichu-Cdc42-expressing NK cell alone (- Target cells). Plots of FRET efficiency against time are shown for the whole conjugate (upper plots) and for the immunological synapses (IS) alone, indicated by arrowheads in (B) (IS \#1 and IS \#2; lower four plots). Error bars in (A) represent the SEM. In all of the examples, except for IS \#2 in the center images where sustained homogeneous activation was seen at the immunological synapse, the FRET efficiency initially increased and then oscillated with a periodicity of about $350 \mathrm{~s}$. The dominant period as determined by power spectrum analysis is indicated in the plots. (B) Representative snapshots from the time-lapse experiments shown in (A). Left to right: epifluorescence images of GFP (green) and DiD (red), a membrane dye that identifies the target 721.221 cells; multiphoton GFP intensity image (gray); a FLIM map of Raichu-Cdc42 FRET efficiency is shown in the look-up table scale at the bottom of the images. White arrowheads indicate areas where the NK cell and target cells come into contact. Scale bars, $10 \mu \mathrm{m}$. (C) Power spectra were plotted for five representative conjugates of Raichu-Cdc42-expressing NK cells and 721.221 target cells, and the dominant periodicity in each case was determined. The plot shows the dominant period and full width at half maximum (FWHM) of the peak. The mean of the five conjugates is also shown. proposed that the oscillatory behavior of Cdc42 activity that we reported (Fig. 1) could be accounted for by feedback loops that include the major regulators of $\mathrm{Cdc} 42$. These assumptions are supported by previously reported data. The $\mathrm{Cdc} 42$ effectors WASP and p21 protein (Cdc42/Rac)activated kinase 1 (PAK1) exist in physical complexes with the GEFs intersectin-1 (35) and Dbl (36), respectively, and thereby enhance their GEF activities. Similarly, a study of budding yeast cells reported that Cdc42 interacts with a downstream protein kinase and an exchange factor (37). Therefore, we postulated that a feedback loop model that involves these regulators would provide a minimal number of key interacting proteins that could then be investigated for their effects on Cdc42 activity with the Raichu-FLIM screen. Specifically, we constructed a subnetwork that included only GEFs, GAPs (GTPase-activating proteins), and signaling molecules (which we chose to restrict to those containing a kinase domain, as in the case of PAK1) that directly interacted with either a GEF or a GAP and with $\mathrm{Cdc} 42$, thus completing a loop (Fig. 2A). The evidence for each interaction (PubMed IDs are given for each interaction in table S1) formed the basis for the selection of siRNA "smart pools." Although ITSN1 and CdGAP were originally selected as targets, reliable knockdown of their mRNAs could not be achieved with these siRNAs in our system (fig. S3A). Vav1 is thought to mediate the activation of RhoA and Rac in hematopoietic cells $(38,39)$. In the case of costimulatory receptor triggering, the time course of tyrosine phosphorylation and activation of Vav1 is linked to that of $\mathrm{Cdc} 42$ after stimulation of the co-receptor CD28 (40). Furthermore, Vav1 is an important regulator of the cytotoxicity of NK cells $(41,42)$. We therefore added Vav1 to our list of candidate proteins in our subnetwork for knockdown (Fig. 2) by relaxing the criterion that a third member of the feedback loop must interact directly with either a GEF or a GAP and with Cdc42 (for example, caspase-3 does not contain a kinase domain).

The cytolytic activity of NK cells, including the release of perforin and granzymes, depends on the integrin lymphocyte function-associated antigen 1 (LFA-1, also known as $\alpha \mathrm{L} \beta 2$ and CD11a/CD18) (43). To establish a positive control for the targeted screen, we tested the effect of a functionblocking monoclonal antibody (mAb, clone 38) against LFA-1 on YTS cells (44). From 
A

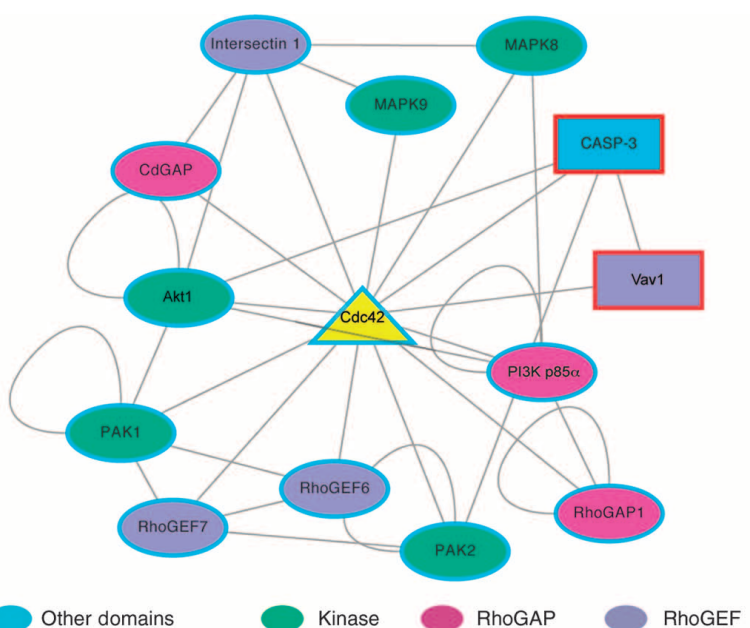

B
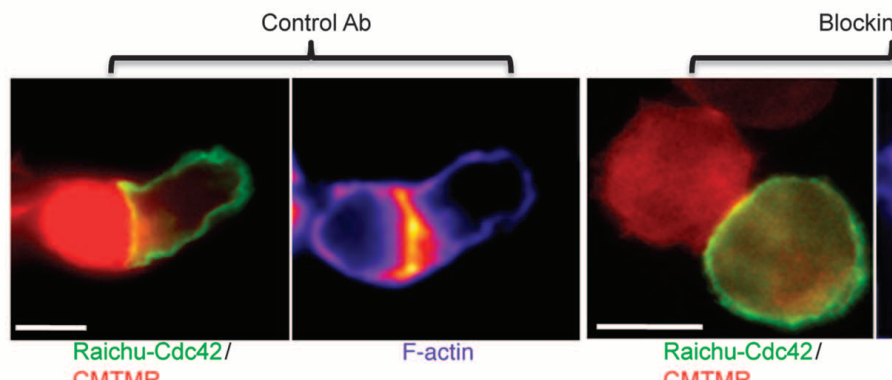

CMTMR
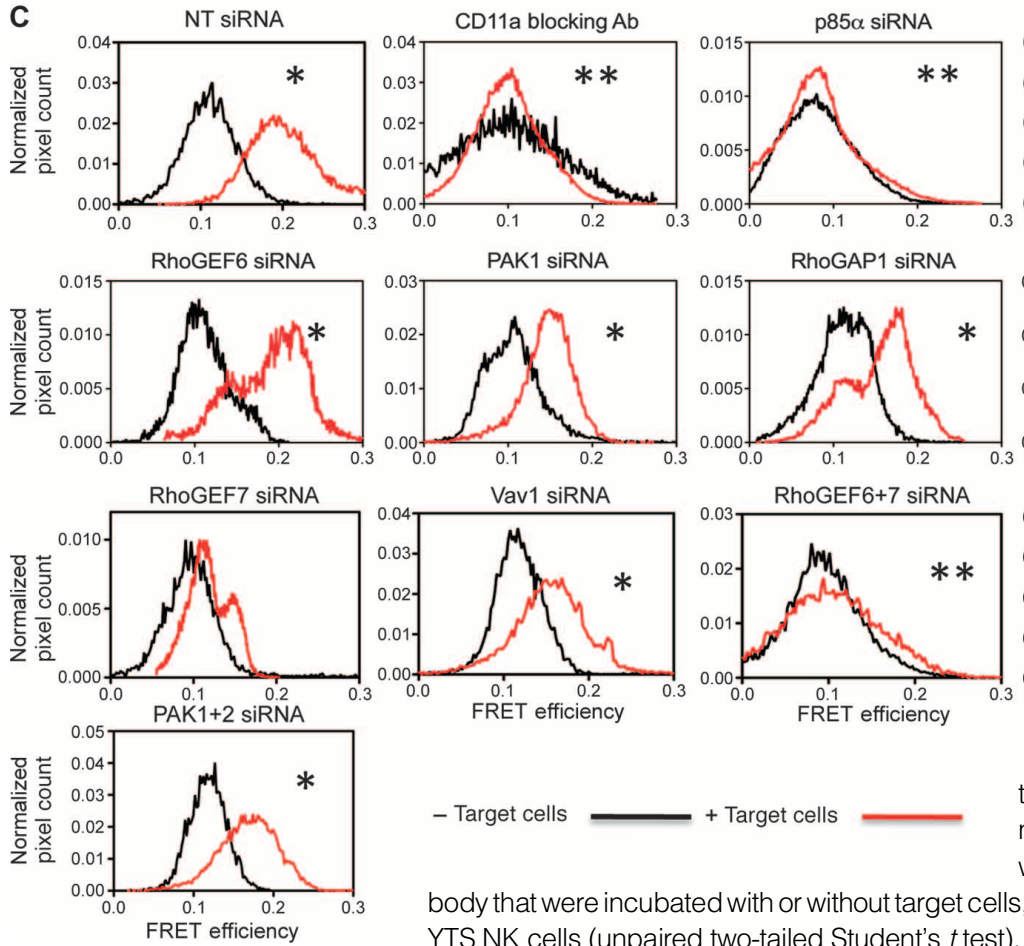

- Target cells

+ Target cells$$
\text { Target cells }
$$

body that were incubated with or without target cells, that is, that the treatment abrogated Cdc42 activity in the conjugated YTS NK cells (unpaired two-tailed Student's $t$ test).
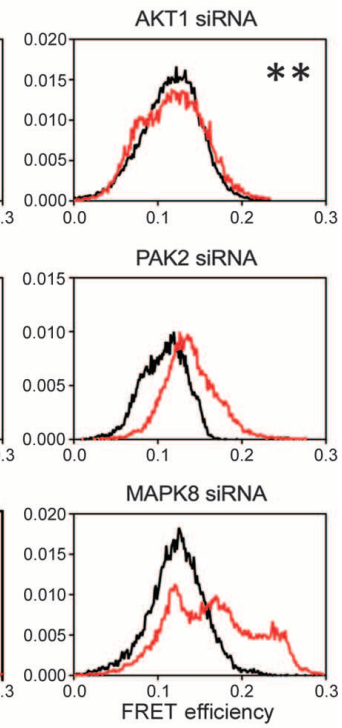

Fig. 2. Use of a Cdc42 interaction subnetwork to predict siRNA targets with a functional role in immune surveillance by NK cells. (A) By mapping protein domain information (fig. S2), we obtained a subnetwork containing proteins that had either a GAP or a GEF domain and interacted with one other member of the full network before interacting with $\mathrm{Cdc} 42$, thus potentially forming feedback loops. High-confidence interactions are connected with black lines. Data from (A) were used to produce a list of targets for knockdown by siRNA. (B) Actin accumulation at the YTS NK cell immunological synapse was inhibited with an antibody that blocks LFA-1 $(\alpha-C D 11 a)$. The left panel of each pair of images shows epifluorescence images of GFP from Raichu-Cdc42 (green) and CMTMR-labeled target cells (red). The right panel of each pair shows the corresponding phalloidin images, which show that $F$-actin did not accumulate when the cellcell interaction was blocked with an antibody against LFA-1 (Blocking $\alpha$ CD11a). Images represent 30 cells from more than three independent experiments. Scale bars, $10 \mu \mathrm{m}$. (C) Pooled Raichu-Cdc42 FRET efficiency histograms ( $n=7$ to 15 cells per experiment from at least three independent experiments). Cells were fixed after 15 min of interaction with or without 721.221 target cells. LFA-1blocking data and siRNA knockdown data for YTS NK cells transfected with the indicated siRNAs that were incubated in the absence (- Target cells, black) or presence (+ Target cells, red) of target cells are shown. ${ }^{*} P \leq$ 0.05 indicates that there was a significant difference in FRET efficiency between the YTS NK cells transfected with the indicated siRNA that were incubated with or without target cells, that is, that there was no effect on Cdc42 activity compared to the control that had not target cells. ${ }^{\star \star} P>0.6$ indicates that there was no significant difference in FRET efficiency between NK cells transfected with the indicated siRNA or incubated with the LFA-1-blocking anti-

$$
\text { , that }
$$

the live-cell kinetic data, we chose a single time point for the screen as well as for the LFA-1-blocking experiment, that is, after $15 \mathrm{~min}$ of interaction with or without target cells, when we consistently saw an increase in Cdc42 activity. Raichu-Cdc42-expressing NK cells were allowed to interact with 721.221 target cells in the presence or absence of the mAb against LFA-1. Fixing the cells and staining for F-actin with fluorescently 
labeled phalloidin revealed that the extent of actin accumulation within the immunological synapse was more than double that of the area outside the immunological synapse (that is, the accumulation was not a result of an increase in signal from cell-cell overlap at the immunological synapse) at the cell-cell contact point in the control cells treated with a nonblocking antibody (Fig. 2B). On the contrary, no increase in the extent of phalloidin staining at the synapse was seen in the presence of the LFA-1-blocking antibody. This increase in F-actin accumulation correlated with an increase in Cdc42 activity, as was demonstrated by Raichu-FLIM in nonblocked cells compared with that in cells in which LFA-1 was blocked (Fig. 2C), thus establishing the nonperturbed and fully perturbed states that served as our positive and negative controls, respectively. These positive and negative controls became the basis for a "first-pass" assay to ascertain the effects of siRNA-based perturbation of candidates on Cdc42 activity.

We cotransfected YTS NK cells with plasmid encoding Raichu-Cdc42 and the appropriate siRNAs; 36 hours later, we fixed the cells 15 min after they had been incubated with or without 721.221 target cells and then we performed imaging (Fig. 2C). We considered the siRNAs to have had an effect on Cdc42 activation when Cdc42-Raichu FRET activity in transfected cells was reduced to that of NK cells in the absence of potential target cells (Fig. 2C). The strongest and most reproducible results were observed with siRNAs against Akt and the p $85 \alpha$ subunit of PI3K. Inhibitors of PI3K (LY294002) and Akt (Akt inhibitor VIII) also reduced the extent of Raichu-Cdc42 activity in NK cell-target cell conjugates to that of NK cells alone (fig. S3G). The other smart pools of siRNA either had little effect (for RhoGEF6, PAK1, RhoGAP1, and Vav1) or had heterogeneous effects [for PAK2, MAPK8 (mitogen-activated protein kinase 8), and RhoGEF7] on Raichu-Cdc 42 activity. In the cases of PAK2 and MAPK8, the intermediate, but insignificant, difference in $\mathrm{Cdc} 42$ activity that occurred upon their knockdown could be accounted for by potentially variable knockdown efficiencies or by their lack of involvement in the regulation of Cdc42 activity (Fig. 2C). When the siRNA smart pools specific for RhoGEF6 (synonymous with $\alpha$-PIX) and RhoGEF 7 (synonymous with $\beta$-PIX) were combined in the same experiment (to address the possibility of functional redundancy or synergy between the two GEFs), we observed a substantial reduction in Cdc42 activity. No such synergy was observed when PAK1and PAK2-specific siRNAs were combined, and there was no effect on Cdc42 activity at the NK immunological synapse (Fig. 2C). Both $\alpha$-PIX and $\beta$-PIX are required for chemoattractant-mediated activation of $\mathrm{Cdc} 42$ (but not Rac1) and PAK1 in hematopoietic cells and other cellular systems (45-47). That the combination of siRNAs targeting RhoGEF6 and RhoGEF7 was more efficient than the targeting of either protein alone in perturbing Cdc42 activity may reflect their location in adjacent and overlapping loops within the human interactome map and therefore potential compensatory effects of the individual GEFs. Therefore, our approach serves as an elegant and stringent way to identify $\mathrm{Cdc} 42$ regulators that have functional effects. Hence, we decided to further examine and validate the effects of knockdown of $\mathrm{p} 85 \alpha$ and Akt on Cdc42 activity.

\section{p85a-SH2 acts as a scaffold for PI3K catalytic activity, which lies on a linear pathway with Akt for regulating Cdc42}

That knockdown of either $\mathrm{p} 85 \alpha$ or Akt by siRNA reduced Cdc42 activity during immune surveillance by NK cells was unexpected, because $\mathrm{p} 85 \alpha$ is a regulatory subunit of $\mathrm{PI} 3 \mathrm{~K}$, and when expressed by itself may exert a dominant inhibitory effect on PI3K activity $(48,49)$. We postulated that $\mathrm{p} 85 \alpha$ acted as a scaffold and thus was required for the proper targeting of the catalytic subunit of PI3K (p110) to generate 3-phosphoinositide lipids for local activation of GEFs. Therefore, we transfected YTS NK cells with plasmid encoding the N-terminal Src homology 2 (SH2) domain of p85 $\alpha$
(p85a-SH2), which lacks the inter-SH2 domain that is required for binding to $\mathrm{p} 110$; therefore, although PI3K regulation would be maintained, its targeting role would be disrupted (Fig. 3). We transfected NK cells with plasmids encoding $\mathrm{p} 85 \alpha-\mathrm{SH} 2$ and Raichu-Cdc42 in a 2:1 ratio, and we confirmed the presence of $\mathrm{p} 85 \alpha-\mathrm{SH} 2$ by immunofluorescence detection of the Myc tag that was fused to p85 $\alpha-\mathrm{SH} 2$ (Fig. 3A). We quantified the effect of p85a-SH2 abundance on Cdc42 activity in YTS NK cells incubated with or without target cells by Raichu-FLIM, as described earlier. The $\mathrm{p} 85 \alpha-\mathrm{SH} 2$ fragment reduced the activity of $\mathrm{Cdc} 42$ relative to that of NK cells incubated alone. The $\mathrm{p} 85 \alpha-\mathrm{SH} 2$ fragment also reduced the basal amount of Cdc42 activity compared to that of control cells (Fig. 3C). Thus, it is likely that the effect of knockdown of p $85 \alpha$ on Cdc42 activity was caused by its role as a scaffold to recruit the catalytic subunit of PI3K to Cdc42, which is consistent with the inhibitory effect of LY294002 on Cdc42 activity (fig. S3G). To demonstrate whether PI3K and Akt lay in a linear regulatory pathway with $\mathrm{Cdc} 42$, and in view of the dependence of Cdc42 activity on LFA-1, which we demonstrated in our NK immunological synapse model (Fig. 2, B and C), we activated YTS NK cells with an activating antibody against LFA-1 (TS1/22) and analyzed cell samples that were untreated or were treated with LY294002 by Western blotting for total Akt and phosphorylated Akt (pAkt). We observed a substantial decrease in the amount of pAkt in cells in which PI3K was inhibited with LY294002 compared to that in untreated cells (Fig. 3D). In LFA-1-ligated NK cells, the activity of Akt was therefore dependent on PI3K input.

\section{Knockdown of p85a or Akt abrogates cytotoxic granule polarization at the NK immunological synapse}

During cytolysis, NK cells direct cytotoxic vesicles to polarize toward the cell-cell interface (50). To look directly at effects downstream of p85 $\alpha$ - or Akt-dependent regulation of Cdc42 activation, we coincubated siRNAtreated, Raichu-Cdc42-expressing YTS cells with 721.221 cells for $30 \mathrm{~min}$ and then stained the cells to detect perforin, which is present in NK cell cytotoxic vesicles. Maximal perforin accumulation in NK cell-target cell conjugates occurs $15 \mathrm{~min}$ after coincubation in suspension followed by $15 \mathrm{~min}$ on poly-L-lysine, for a total of $30 \mathrm{~min}(51)$. At this time point, we found that $57 \%$ of the NK cell-target cell conjugates imaged after treatment with control siRNA exhibited polarized vesicles toward the target cell (Fig. 4, A and B). When p $85 \alpha$ was knocked down, only $20 \%$ of the cells showed polarized granules, and when Akt1 was knocked down, only $15 \%$ of cells showed granule polarization (Fig. 4B). These results suggest that as well as reducing conjugation-triggered $\mathrm{Cdc} 42$ activity, knockdown of $\mathrm{p} 85 \alpha$ or Akt also inhibited granule polarization. Polarization of cytotoxic vesicles is associated with cytoskeletal remodeling and relocation of the microtubuleorganizing center (MTOC) during cytotoxicity $(16,51)$.

\section{PI3K regulates the oscillation in Cdc42 activity at the NK immunological synapse}

We also demonstrated that in addition to perturbing the initial rise in $\mathrm{Cdc} 42$ activity at the immunological synapse, RNAi-mediated knockdown of p $85 \alpha$ also abrogated oscillations in Cdc42 activity (Fig. 4C). The Cdc42dependent positioning of the MTOC is consistent with previous observations of T cells interacting with targets (38) and other nonimmune cell types (52). As stated, p85a-specific siRNA completely abrogated both the increase in Cdc42 activity and its oscillation; however, if p $85 \alpha$ is not available at the initiation of the immunological synapse, then this is perhaps not a surprising observation. Therefore, we performed live-cell imaging experiments in which either dimethyl sulfoxide (DMSO) (as a vehicle control) or LY294002 was added to the cells upon formation of the immunological synapse. Compared with the oscillation in Cdc42 activity observed in DMSO-treated cells, the oscillation in LY294002-treated 
Fig. 3. The $\mathrm{p} 85 \alpha \mathrm{SH} 2$ domain reduces the extent of $\mathrm{Cdc} 42$ activation. (A) NK cells were mock-transfected (control) or were transfected with plasmids encoding p85-SH2 and Raichu-Cdc42 in a 2:1 ratio. Micrographs show detection of the Myc tag on the p85-SH2 construct in red. (B) Representative images of YTS NK cells with (bottom) or without (top) the p85 $\alpha$-SH2 domain construct in the absence or presence of target cells. Epifluorescence (left image of each pair) shows Raichu-Cdc42 (green) and CMTMR (red), whereas the FLIM images (right image of each pair) show FRET efficiency according to the indicated color scale. Data represent 15 cells from more than three independent experiments. (C) Pooled FRET efficiency histogram data ( $n>15$ cells per condition from three independent experiments) from cells with (bottom) or without (top) p85-SH2. ${ }^{*} P \leq 0.05$ indicates that there was a significant difference in the FRET efficiency between those mocktransfected NK cells that were incubated alone and those that were incubated with target cells. ${ }^{\star *} P>0.9$ indicates that there was no significant difference in the FRET efficiency between YTS NK cells that contained the p85-SH2 construct and were incubated alone and those that were incubated with target cells; that is, the Raichu-Cdc42 activity was reduced to that of control NK cells that were not incubated with target cells (unpaired, two-tailed Student's $t$ test). (D) Representative Western blot showing pAkt and total Akt in YTS NK cells stimulated with an LFA-1-activating antibody (TS1/22) in the presence of DMSO or LY294002. The relative intensity of the pAkt band in the presence of LY294002 (from three experiments) was $44.0 \pm 9 \%$ of that in the DMSO-treated sample. $P<0.05$, by unpaired, twotailed Student's $t$ test. Scale bars, $10 \mu \mathrm{m}$.

cells was decreased in amplitude and frequency (Fig. 4, D and E). The effect of the inhibition of PI3K on the oscillation in Cdc42 activity suggested that PI3K regulated $\mathrm{Cdc} 42$ oscillation independently of the initial increase in $\mathrm{Cdc} 42$ activity.

\section{DISCUSSION}

Cdc42 is implicated in a number of cellular mechanisms that are important for NK function. Here, we used a FRET biosensor to investigate the spatiotemporal activity of $\mathrm{Cdc} 42$ in a model of live human NK cells surveying potential target cells. Whereas it is perhaps expected that the general extent of Cdc42 activity within NK cells should increase when they need to rapidly reorganize their actin cytoskeleton if a potential target cell is encountered [remodeling of the actin cytoskeleton is associated with immune surveillance by $\mathrm{T}$ cells and NK cells $(53,54)$, we made the additional observation that $\mathrm{Cdc} 42$ activity oscillated with a periodicity of 300 to 375 s. Our previous study with Raichu-FLIM, which combined experimental data and theoretical prediction, showed an initial increase in Cdc42 activity that subsequently reached an equilibrium in T lymphocytes spread on integrin substrates (5), but we did not observe any oscillations in activity. It is thought that the polarization of the cytoskeleton that is required for NK cell-mediated cytotoxicity occurs through multistep serial control, which contrasts with the situation in T cells (20). A more complicated feedback control of a key signal integrator such as $\mathrm{Cdc} 42$ would fit with this observation.

Dynamic turnover of macrophage membrane protrusions, which consist of fine filopodia and membrane ruffles that are associated with targets, have been observed at a very early stage of phagocytosis (55). This dynamic macrophage "probing" is also reminiscent of the cyclic protrusion and contraction of the membrane edges of $\mathrm{T}$ cells that are undergoing receptor-specific adhesion on artificial lipid bilayers containing intercellular adhesion molecule-1 (ICAM-1), a ligand of LFA-1 (32). Whereas the protrusion and contraction cycles have a regular periodicity of $42 \mathrm{~s}$,
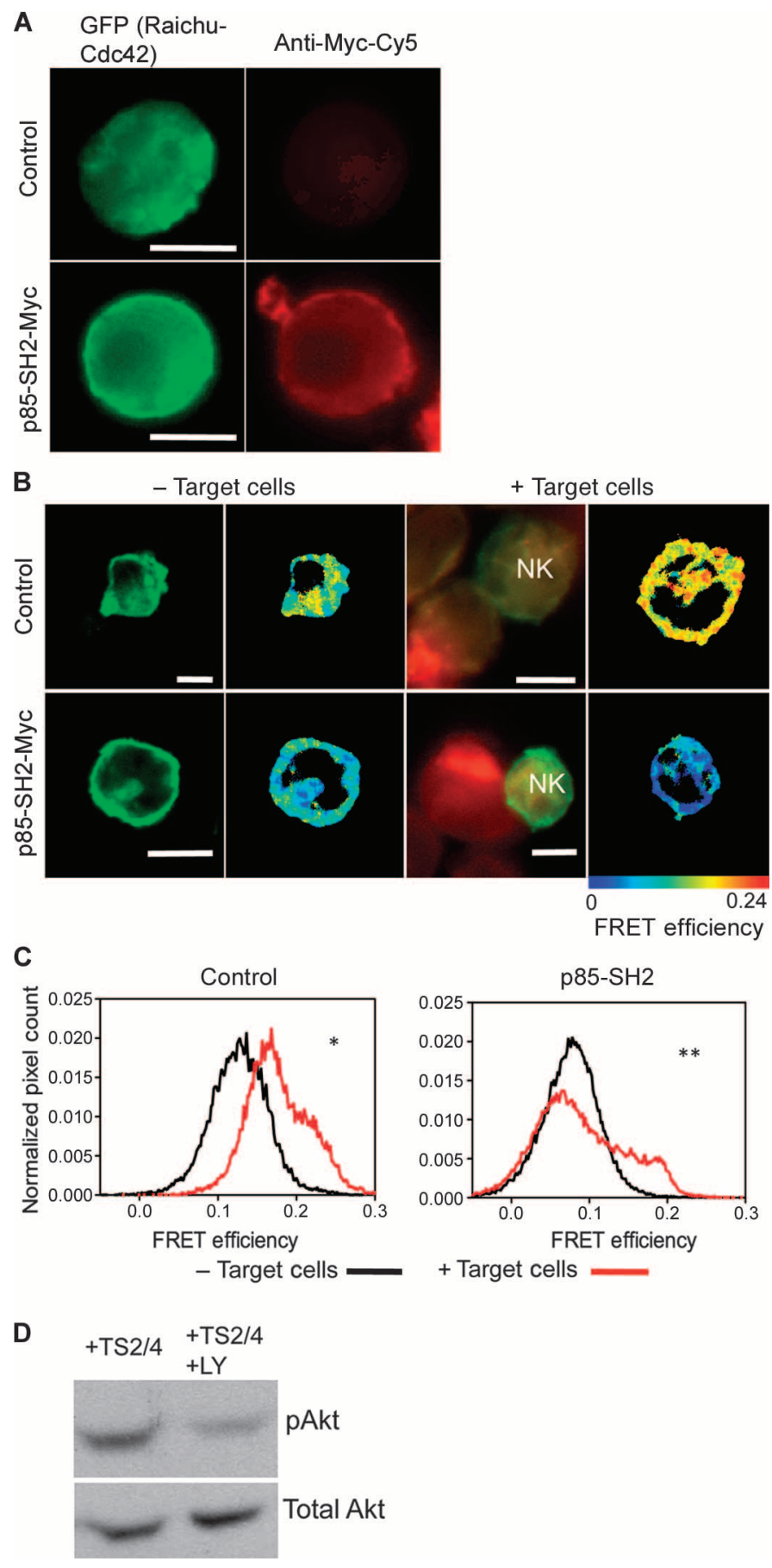

whether Rho GTPase activity follows a similar oscillatory pattern has to our knowledge not been investigated. Here, we report that Cdc42 activity oscillates with a regular periodicity of 300 to $375 \mathrm{~s}$ in our experimental system of cell-cell interaction (Fig. 1C). In addition, through a subnetwork composed of possible $\mathrm{Cdc} 42$ regulators, which was informed by bioinformatics analysis, we identified and validated PI3K and Akt, which are both highly abundant in NK cells in comparison with other leukocytes $(56,57)$, as controllers of the observed oscillatory increase in Cdc42 activity at the NK cell immunological synapse. In PC12 cells monitored with various 
A Overlay

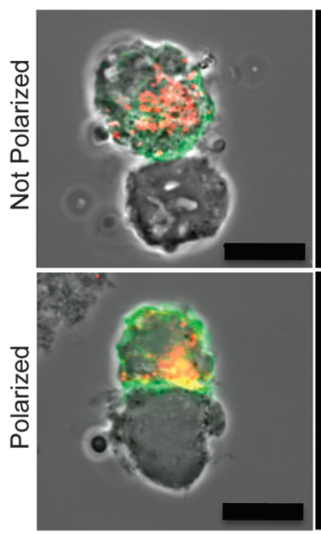

C

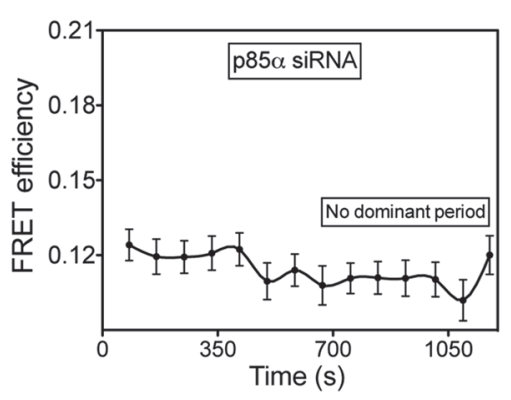

D

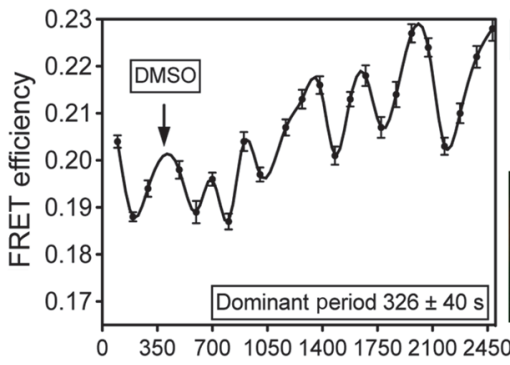

E

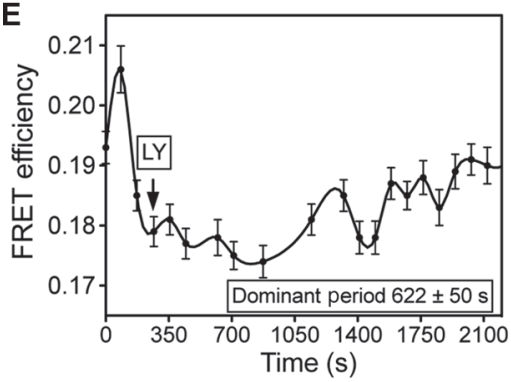

B

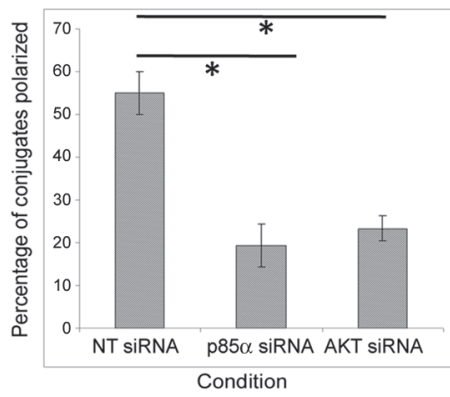

Fig. 4. Inhibition of $p 85 \alpha$ or Akt function diminishes polarization of cytotoxic vesicles toward the immunological synapse, abrogates Cdc42 activity, and perturbs Cdc42 oscillation. (A) Maximum intensity projections of confocal image stacks of Raichu-Cdc42-expressing YTS NK cells interacting with target 721.221 cells. Transmitted light (gray), GFP fluorescence from RaichuCdc42 (green), and Cy5 fluorescence from antibody against perforin (red) are presented in an overlay and are shown separately. Images on the top row are from an NK cell that was treated with smart pool siRNA against Akt1; perforin-containing vesicles were not polarized. The images on the bottom row are from an NK cell that was treated with a nontargeting siRNA pool; perforincontaining vesicles were polarized toward the cellcell interface. Data represent three independent experiments. (B) Pooled data from multiple siRNA-based knockdown experiments. Bar chart shows the percentage of cells that showed perforincontaining vesicles polarized toward the immunological synapse. Polarized and nonpolarized cells were counted by a researcher blinded to the experimental condition. More than 25 cells were counted per experiment from more than three experiments ${ }^{*} P \leq 0.05$, unpaired two-tailed Student's $t$ test. Scale bar, $10 \mu \mathrm{m}$. (C) FRET efficiency of Raichu-Cdc42 over time in an YTS NK celltarget cell conjugate in which the NK cell was treated with

p85 $\alpha$-specific siRNA. No increase above basal activity was observed, nor was there any oscillation in Cdc42 activity. Epifluorescence images of GFP (green) and DiD (red) are shown on the left; multiphoton GFP intensity images (gray) are shown in the center panels; and FLIM maps of Raichu-Cdc42 FRET efficiency are shown in the images on the right. See the table scale underneath the images to determine FRET efficiency. Frame times are given in seconds (s). ( $\mathrm{D}$ and $\mathrm{E}$ ) Representative time-lapse data ( $n>5$ cells per condition from more than three independent experiments) YTS NK cells were allowed to form immunological synapses with target cells. At the times indicated in the plots, either (D) DMSO as a vehicle control or (E) LY294002 $(10 \mu \mathrm{M})$ was added to the culture medium. Dominant periods from power spectra are indicated on the graphs. Representative images are shown as described for (C). Error bars represent SEM. Scale bar, $10 \mu \mathrm{m}$. 
intensity-based FRET sensors, the production of phosphatidylinositol 3,4,5-trisphosphate $\left(\mathrm{PIP}_{3}\right)$ by $\mathrm{PI} 3 \mathrm{~K}$ has been linked in time with the activation of Cdc42 upon stimulation with growth factors (58), lending support to the hypothesis that a positive feedback loop exists between Cdc42 and PI3K.

Previous work has implicated $\mathrm{p} 85 \alpha$ in NK cell function. Mouse $\mathrm{p} 85 \alpha$ knockout NK cells have reduced cytotoxic activity and cytokine production compared to those of wild-type NK cells (59), although a direct link between $\mathrm{p} 85 \alpha$ and $\mathrm{Cdc} 42$ activity has not been demonstrated. p $85 \alpha$ acts downstream of NKG2D activation by inhibiting the Crk-like protein CrkL, which reduces the extent of MTOC reorientation and cytotoxicity (60); however, NKG2D is not found on YTS NK cells (61), so it seems likely that another upstream signaling pathway is involved. In addition, siRNAmediated knockdown of Vav1 had no effect on Cdc42 activity in our assay despite its demonstrated role in NK cytotoxicity $(41,42)$. Vav2 and Vav3 are also thought to be important in regulating NK cytotoxicity in response to upstream signaling (62); however, both of these Vav isoforms are not part of a three-member feedback loop and therefore were not included in our subnetwork-based screen.

When RhoGEF6 ( $\alpha$-PIX) and RhoGEF7 ( $\beta$-PIX) were both knocked down, we observed a substantial reduction in Cdc42 activity in the NK cell immunological synapse. The PAK-interacting exchange factor (PIX) family members act as GEFs to mediate the activation of Rac1 and Cdc42 (46). In hematopoietic cells, such as T lymphocytes (63), as well as in cancer cells (64), PIX proteins serve as scaffold proteins by binding to paxillin and paxillin kinase linker p95PKL, a member of the heterotrimeric guanosine triphosphate-binding protein (G protein)-coupled receptor kinaseinteracting 2 (GIT2)/PKL family, which is a paxillin-binding protein with an adenosine diphosphate ribosylation factor (ARF)-GAP domain. This interaction results in the formation of the GIT-PIX-paxillin complex, which contributes to the spatially determined activation of Rac1 and Cdc42 (65). We therefore tested whether knocking down both PAK1 and PAK2 simultaneously might feedback on $\mathrm{Cdc} 42$ activity through their potential scaffold function by their potential interactions with the PIX proteins; however, we saw no such effect (Fig. 2C).

Downstream of $\mathrm{Cdc} 42$ activity, effects on vesicle polarization that are essential for NK cell function confirmed that two nodes, PI3K and Akt, within the $\mathrm{Cdc} 42$ interaction subnetwork provided positive feedback for $\mathrm{Cdc} 42$ activation and its consequent effect on the targeting of lytic granules toward target cells. Given these findings, it would be important to investigate the functional relevance of this phenomenon to other pathophysiological contexts of disease surveillance, regardless of whether the immune cells performing surveillance are innate, for example, in the aforementioned Rho GTPase-dependent phagocytosis of pathogens by macrophages $(55,66)$, or adaptive, for example, antigen-specific cytolytic T cells (67).

We propose that, as in the case of the oscillatory nuclear translocation of the transcription factor nuclear factor NF $\kappa \mathrm{B}(\mathrm{NF}-\kappa \mathrm{B})$ and its correlation with function (that is, gene expression) $(68,69)$, a proper understanding of regulatory control modules within immune cells that influence the periodicity of the oscillatory activation of Rho GTPases will fundamentally improve our understanding of immunological function in various physiological and pathological states, such as cancers and infections, and autoimmune conditions, such as arthritis and diabetes. Our discovery of the role of PI3K in regulating the process of cell-cell communication (in this case, NK cell-mediated immunosurveillance) through a cytoskeleton-driven vesicle trafficking mechanism is also likely to be of interest to a broad range of immune cell signaling fields (70). This study shows that a multidisciplinary combination of imaging techniques that identify the spatiotemporal activities of molecular switches in living cells, bioinformatics-driven experimental design, and controllable in situ gene silencing can yield advances in our understanding of molecular mechanisms in living immune cells.

\section{MATERIALS AND METHODS}

\section{Cells and antibodies}

The YTS cell line is a subclone of a human NK cell-like cell line (71), and 721.221 is a human Epstein-Barr virus (EBV)-transformed B cell line that was mutated to express no HLA-A (human lymphocyte antigen A), -B, or -C (72). Both cell lines were cultured in RPMI 1640, as described previously (73). The clone $38 \mathrm{mAb}$ against LFA-1 (Cancer Research UK/Autogen Bioclear) was used as a blocking antibody.

\section{FLIM-FRET measurements of Cdc42 activity}

Multiphoton, time-correlated single-photon counting (TCSPC) FLIM was performed to quantify changes in the activity of the Raichu-Cdc42 biosensor by FRET. A Nikon TE2000E inverted microscope combined with an in-house scanner (74) and Ti:Sapphire laser (Coherent) was used for multiphoton excitation of GFP. All images were acquired at a suitable spatial and time resolution to provide enough photon arrival times to enable fitting of accurate fluorescence decay while avoiding detector "pile-up" and were analyzed by performing a single-exponential pixel fit in TRI2 time-resolved image analysis software $(5-7,28,74)$.

\section{Sample fixation}

YTS NK cells were transiently transfected by electroporation with mRFP1-Cdc42Raichu-eGFP plasmid (referred to as Raichu-Cdc42), as described previously $(5,6)$, as well as with 250 to $480 \mathrm{nM}$ siRNA (ONTARGETplus SMARTpools, Dharmacon), where stated. After 36 hours, 721.221 target cells were incubated with CellTracker Orange CMTMR [5(and-6)-(((4-chloromethyl)benzoyl)amino)tetramethylrhodamine] (Invitrogen). YTS NK cells and 721.221 target cells were mixed in a ratio of 1:2 in $100 \mu \mathrm{l}$ of conditioned medium at $37^{\circ} \mathrm{C}$ in $5 \% \mathrm{CO}_{2}$ for $15 \mathrm{~min}$ and then were fixed with $4 \%$ paraformaldehyde. Where inhibitors (at the concentrations stated in the legends) or the LFA-1-blocking mAb $(10 \mu \mathrm{g} / \mathrm{ml})$ was used, the YTS NK cells were preincubated with the reagents for 1 hour. Coverslips were mounted in Mowiol (Sigma) containing Dabco (1,4diazabicyclo[2.2.2]octane; Calbiochem) and imaged with a 40×, $1.4 \mathrm{nu}-$ merical aperture (NA) oil-immersion objective lens. Epifluorescence images were acquired through fluorescein isothiocyanate (FITC) (GFP), G2A (CMTMR), and Cy5 (DiD) filter sets (Chroma) on a charge-coupled device (CCD) camera (Orca, Hamamatsu).

\section{Statistical analysis}

Pooled FRET efficiency histograms were fitted to Gaussians to calculate mean and SD values for each condition with and without target cells. $P$ values are from unpaired, two-tailed Student's $t$ tests performed for each condition (siRNA, LFA-1-blocking mAb, or inhibitor) to compare NK cells in the presence or absence of target cells with $n$ values from each experiment. For other statistical analysis, two-tailed Student's $t$ tests were used.

\section{Live samples}

YTS NK cells were transiently transfected with Raichu-Cdc 42 by electroporation, as described previously $(5,6)$. The 721.221 target cells were stained for $5 \mathrm{~min}$ at $37^{\circ} \mathrm{C}$ in $5 \% \mathrm{CO}_{2}$ with Vybrant DiD labeling solution ( $5 \mu \mathrm{M}$; Invitrogen), washed, and left in complete medium for $30 \mathrm{~min}$ at $37^{\circ} \mathrm{C}$ in $5 \% \mathrm{CO}_{2}$. YTS NK cells were then transferred to live-cell imaging chambers (Nunc/WaferGen/lbidi) and maintained at $37^{\circ} \mathrm{C}$ in $5 \% \mathrm{CO}_{2}$, and 
721.221 cells were added at about a 1:1 ratio at the commencement of imaging. In the live-cell PI3K inhibition experiments, at the times indicated after commencement of imaging an NK cell-target cell conjugate, either DMSO or LY294002 $(10 \mu \mathrm{M})$ was introduced to the culture medium. Images were analyzed with TRI2 $(5-7,74)$ and ImageJ software (75).

Reverse transcription-polymerase chain reaction assays Up to $1 \mu \mathrm{g}$ of RNA was reverse-transcribed into complementary DNA (cDNA) in a total volume of $20 \mu \mathrm{l}$ with SuperScript III First-Strand Synthesis SuperMix for real-time reverse transcription-polymerase chain reaction (RT-PCR) analysis according to the manufacturer's instructions. The RT reaction was prepared on ice by combining RT enzyme mix (which included SuperScript III and RNAseOUT) and $2 \times$ RT reaction mix [including $2.5 \mu \mathrm{M}$ oligo(dT) $)_{20}$, random hexamers $(2.5 \mathrm{ng} / \mu \mathrm{l}), 10 \mathrm{mM} \mathrm{MgCl}_{2}$, and $10 \mathrm{mM}$ deoxynucleotide triphosphates (dNTPs)] with up to $1 \mu \mathrm{g}$ of total RNA. The volume was made up to a total of $20 \mu 1$. The components were gently mixed and incubated at $25^{\circ} \mathrm{C}$ for $10 \mathrm{~min}$ followed by incubation at $50^{\circ} \mathrm{C}$ for $30 \mathrm{~min}$. The reaction was terminated by incubation at $85^{\circ} \mathrm{C}$ for $5 \mathrm{~min}$, and reactions were then chilled on ice. The single-stranded cDNA was treated with $2 \mathrm{U}$ of RNase $\mathrm{H}$ (ribonuclease $\mathrm{H}$ ) for $20 \mathrm{~min}$ at $37^{\circ} \mathrm{C}$. The cDNA was diluted in tris-EDTA to up to $30 \mu \mathrm{l}$ and kept at $-20^{\circ} \mathrm{C}$ for long-term storage. Real-time PCR analysis was performed with SYBR Green incorporation to determine the extent of expression of the target genes after transfection of cells with various siRNAs (see fig. S1 for primer sequences). A $25-\mu 1$ reaction mixture contained $1 \times$ Platinum SYBR Green qPCR SuperMix-UDG with ROX, 3 pmol each of the forward and reverse primers, and $3 \mu \mathrm{l}$ of cDNA. Real-time PCR was performed on an ABI PRISM 7900 instrument (Applied Biosystems). Reaction conditions were incubation at $50^{\circ} \mathrm{C}$ for $2 \mathrm{~min}, 95^{\circ} \mathrm{C}$ for $10 \mathrm{~min}$, followed by 40 cycles of incubation at $95^{\circ} \mathrm{C}$ for $15 \mathrm{~s}$ and at $60^{\circ} \mathrm{C}$ for $60 \mathrm{~s}$. All determinations were performed in triplicate. The $C_{\mathrm{T}}$ method (76) was applied to estimate relative transcription levels. $A B L 1$ mRNA was used as an endogenous reference to normalize each sample.

\section{Western blotting analysis}

Twenty-four hours after transfection with siRNA, $1 \times 10^{6}$ to $2 \times 10^{6}$ YTS NK cells were lysed in $1.3 \times$ LDS (lithium dodecyl sulfate) sample buffer for $20 \mathrm{~min}$ at $95^{\circ} \mathrm{C}$ [ $4 \times \mathrm{LDS}$ sample buffer contains $106 \mathrm{mM}$ tris- $\mathrm{HCl}, 141$ $\mathrm{mM}$ tris base, $2 \% \mathrm{LDS}, 10 \%$ glycerol, and $0.5 \mathrm{mM}$ EDTA (pH 8.5)]. After determination of the protein concentration by BCA (bicinchoninic acid) assay, protease inhibitor cocktail (Sigma Aldrich), $10 \mathrm{mM}$ dithiothreitol, and $0.22 \mathrm{mM}$ Serva Blue G250 were added to the samples. All lysates were incubated for $5 \mathrm{~min}$ at $95^{\circ} \mathrm{C}$ and were then resolved on 4 to $12 \%$ polyacrylamide bis-tris gels by electrophoresis at $200 \mathrm{~V}$ for 1 hour in running buffer [50 mM MES, $50 \mathrm{mM}$ tris, $1 \mathrm{mM}$ EDTA, and $0.1 \%$ SDS ( $\mathrm{pH}$ 7.3); Invitrogen] together with a protein standard (Novex, Invitrogen). Gels were transferred by electroblotting at 30 to $40 \mathrm{~V}$ for 1 hour to a nitrocellulose membrane (Hybond-C Extra, GE Healthcare) in NuPage transfer buffer $[25 \mathrm{mM}$ bis-tris, $25 \mathrm{mM}$ bicine, and $1 \mathrm{mM}$ EDTA $(\mathrm{pH}$ 7.2)] containing $20 \%$ methanol. The membrane was blocked by incubation in phosphate-buffered saline (PBS) containing $0.1 \%$ Tween 20 (PBST) with 3 to $4 \%$ bovine serum albumin (BSA) for $30 \mathrm{~min}$ at room temperature. The blot was washed once with PBST before being incubated with antibody. Primary antibodies were typically used at dilutions of $1: 1000$ in PBST with $3 \%$ BSA and $0.01 \% \mathrm{NaN}_{3}$. Blots were incubated in primary antibodies overnight and then were washed three times for $5 \mathrm{~min}$ in PBST before being incubated in secondary antibody for $30 \mathrm{~min}$. Secondary antibodies from Dako and Amersham were used. Blots were washed three times, and protein bands were detected with the Pierce ECL WB Substrate (Thermo Scientific) and exposed to x-ray film (Hyperfilm-
ECL, GE Healthcare) for various periods of time. Primary antibodies used in the experiments were antibody against Akt1 (C73H10) from Cell Signaling, antibody against $\mathrm{Rb}$ from $\mathrm{BD}$ Pharmingen, antibodies against RhoGEF6 (C23D2) and RhoGEF7 from Cell Signaling, antibody against Vav (Santa Cruz), and antibody against glyceraldehyde-3-phosphate dehydrogenase (GAPDH) (14C10, Cell Signaling). For analysis of pAkt by Western blotting, $1 \times 10^{6}$ YTS cells were centrifuged at $200 \mathrm{~g}$ and resuspended in $100 \mu \mathrm{l}$ of Hepes buffer ( $20 \mathrm{mM}$ Hepes containing $5 \mathrm{mM}$ $\mathrm{MgCl}_{2}$ and $1 \mathrm{mM}$ EDTA). Cells were preincubated for $30 \mathrm{~min}$ at $37^{\circ} \mathrm{C}$ with or without LY294002 (10 $\mu \mathrm{M}$, Cell Signaling). After $30 \mathrm{~min}$, mouse monoclonal activating pan-LFA-1 antibody $(10 \mu \mathrm{g} / \mathrm{ml}, \mathrm{TS} 2 / 4)$ was added to the cells and the samples were incubated at $37^{\circ} \mathrm{C}$ for a further $15 \mathrm{~min}$. The cells were then centrifuged at $200 \mathrm{~g}$ for $8 \mathrm{~min}$ and resuspended in $1.1 \times$ LDS lysis buffer $(100 \mathrm{ml})$, heated for $20 \mathrm{~min}$ at $100^{\circ} \mathrm{C}$, and centrifuged at $15,000 \mathrm{~g}$ The lysates were resolved on a 4 to $12 \%$ bis-tris gel and transferred onto polyvinylidene difluoride membrane. The membranes were blocked in $5 \%$ milk in tris-buffered saline (TBS) containing $0.1 \%$ Tween 20 for 1 hour at room temperature. The membranes were incubated with primary antibody diluted in TBS and $0.1 \%$ Tween 20 containing 5\% $\mathrm{BSA}$ at $4^{\circ} \mathrm{C}$ overnight. The antibodies used were against pAkt $\mathrm{Ser}^{473}$ (D9E) and total Akt (C73H10) and were obtained from Cell Signaling. Western blot images were analyzed with ImageJ software (75).

\section{SUPPLEMENTARY MATERIALS}

www.sciencesignaling.org/cgi/content/full/4/201/ra81/DC1

Fig. S1. Diagram of the Raichu-Cdc42 biosensor and time-lapse live-cell FLIM analysis of a representative NK cell containing Cdc42-GFP.

Fig. S2. Cdc42 protein interaction network and $i$ PFAM scoring method.

Fig. S3. Quantification of siRNA-mediated knockdown and Raichu-FLIM for fixed cell inhibitor experiments.

Table S1. Table of PubMed IDs for interaction evidence used to prepare the interaction subnetwork.

Movie S1. Time-lapse live-cell Raichu-FLIM movie showing a YTS NK cell interacting with two 721.221 target cells, including an animated plot of the mean FRET efficiency of Raichu-Cdc42.

\section{REFERENCES AND NOTES}

1. A. J. Ridley, Rho GTPases and actin dynamics in membrane protrusions and vesicle trafficking. Trends Cell Biol. 16, 522-529 (2006).

2. K. Kurokawa, R. E. Itoh, H. Yoshizaki, Y. O. Nakamura, M. Matsuda, Coactivation of Rac1 and Cdc42 at lamellipodia and membrane ruffles induced by epidermal growth factor. Mol. Biol. Cell 15, 1003-1010 (2004).

3. P. Nalbant, L. Hodgson, V. Kraynov, A. Toutchkine, K. M. Hahn, Activation of endogenous Cdc42 visualized in living cells. Science 305, 1615-1619 (2004).

4. O. Pertz, L. Hodgson, R. L. Klemke, K. M. Hahn, Spatiotemporal dynamics of RhoA activity in migrating cells. Nature 440, 1069-1072 (2006).

5. K. Makrogianneli, L. M. Carlin, M. D. Keppler, D. R. Matthews, E. Ofo, A. Coolen, S. M. Ameer-Beg, P. R. Barber, B. Vojnovic, T. Ng, Integrating receptor signal inputs that influence small Rho GTPase activation dynamics at the immunological synapse. Mol. Cell. Biol. 29, 2997-3006 (2009).

6. L. M. Carlin, K. Makrogianneli, M. Keppler, G. O. Fruhwirth, T. Ng, Visualisation of signalling in immune cells. Methods Mol. Biol. 616, 97-113 (2010).

7. P. R. Barber, S. M. Ameer-Beg, J. Gilbey, L. M. Carlin, M. Keppler, T. C. Ng, B. Vojnovic, Multiphoton time-domain fluorescence lifetime imaging microscopy: Practical application to protein-protein interactions using global analysis. J. R. Soc. Interface 6, S93-S105 (2009).

8. D. R. Matthews, L. M. Carlin, E. Ofo, P. R. Barber, B. Vojnovic, M. Irving, T. Ng, S. M. Ameer-Beg, Time-lapse FRET microscopy using fluorescence anisotropy. J. Microsc. 237, 51-62 (2010)

9. M. Beutler, K. Makrogianneli, R. J. Vermeij, M. Keppler, T. Ng, T. M. Jovin, R. Heintzmann, satFRET: Estimation of Förster resonance energy transfer by acceptor saturation. Eur. Biophys. J. 38, 69-82 (2008).

10. S. J. Heasman, L. M. Carlin, S. Cox, T. Ng, A. J. Ridley, Coordinated RhoA signaling at the leading edge and uropod is required for T cell transendothelial migration. J. Cell Biol. 190, 553-563 (2010). 
11. T. Nakamura, K. Aoki, M. Matsuda, Monitoring spatio-temporal regulation of Ras and Rho GTPase with GFP-based FRET probes. Methods 37, 146-153 (2005).

12. J. U. Hwang, Y. Gu, Y. J. Lee, Z. Yang, Oscillatory ROP GTPase activation leads the oscillatory polarized growth of pollen tubes. Mol. Biol. Cell 16, 5385-5399 (2005).

13. G. Trinchieri, Biology of natural killer cells. Adv. Immunol. 47, 187-376 (1989).

14. D. M. Davis, I. Chiu, M. Fassett, G. B. Cohen, O. Mandelboim, J. L. Strominger, The human natural killer cell immune synapse. Proc. Natl. Acad. Sci. U.S.A. 96, 15062-15067 (1999).

15. Y. M. Vyas, K. M. Mehta, M. Morgan, H. Maniar, L. Butros, S. Jung, J. K. Burkhardt, B. Dupont, Spatial organization of signal transduction molecules in the NK cell immune synapses during MHC class I-regulated noncytolytic and cytolytic interactions. J. Immunol. 167, 4358-4367 (2001).

16. Y. M. Vyas, H. Maniar, B. Dupont, Visualization of signaling pathways and cortica cytoskeleton in cytolytic and noncytolytic natural killer cell immune synapses. Immunol. Rev. 189, 161-178 (2002).

17. A. Gismondi, L. Cifaldi, C. Mazza, S. Giliani, S. Parolini, S. Morrone, J. Jacobelli, E. Bandiera L. Notarangelo, A. Santoni, Impaired natural and CD16-mediated NK cell cytotoxicity in patients with WAS and XLT: Ability of IL-2 to correct NK cell functional defect. Blood 104, 436-443 (2004).

18. D. M. Davis, M. L. Dustin, What is the importance of the immunological synapse? Trends Immunol. 25, 323-327 (2004).

19. F. J. Culley, M. Johnson, J. H. Evans, S. Kumar, R. Crilly, J. Casasbuenas, T. Schnyder M. Mehrabi, M. P. Deonarain, D. S. Ushakov, V. Braud, G. Roth, R. Brock, K. Kohler D. M. Davis, Natural killer cell signal integration balances synapse symmetry and migration. PLoS Biol. 7, e1000159 (2009)

20. C. Wulfing, B. Purtic, J. Klem, J. D. Schatzle, Stepwise cytoskeletal polarization as a series of checkpoints in innate but not adaptive cytolytic killing. Proc. Natl. Acad. Sci. U.S.A. 100, 7767-7772 (2003)

21. M. L. Dustin, J. A. Cooper, The immunological synapse and the actin cytoskeleton: Molecular hardware for T cell signaling. Nat. Immunol. 1, 23-29 (2000).

22. K. S. Weber, L. B. Klickstein, P. C. Weber, C. Weber, Chemokine-induced monocyte transmigration requires cdc42-mediated cytoskeletal changes. Eur. J. Immunol. 28 2245-2251 (1998)

23. M. A. del Pozo, M. Vicente-Manzanares, R. Tejedor, J. M. Serrador, F. Sanchez-Madrid, Rho GTPases control migration and polarization of adhesion molecules and cytoskeletal ERM components in T lymphocytes. Eur. J. Immunol. 29, 3609-3620 (1999).

24. C. D. Nobes, A. Hall, Rho GTPases control polarity, protrusion, and adhesion during cell movement. J. Cell Biol. 144, 1235-1244 (1999).

25. B. Stramer, W. Wood, M. J. Galko, M. J. Redd, A. Jacinto, S. M. Parkhurst, P. Martin, Live imaging of wound inflammation in Drosophila embryos reveals key roles for small GTPases during in vivo cell migration. J. Cell Biol. 168, 567-573 (2005).

26. R. E. Itoh, K. Kurokawa, Y. Ohba, H. Yoshizaki, N. Mochizuki, M. Matsuda, Activation of Rac and Cdc42 video imaged by fluorescent resonance energy transfer-based singlemolecule probes in the membrane of living cells. Mol. Cell. Biol. 22, 6582-6591 (2002)

27. H. Yoshizaki, Y. Ohba, K. Kurokawa, R. E. Itoh, T. Nakamura, N. Mochizuki, K. Nagashima M. Matsuda, Activity of Rho-family GTPases during cell division as visualized with FRETbased probes. J. Cell Biol. 162, 223-232 (2003).

28. F. Festy, S. M. Ameer-Beg, T. Ng, K. Suhling, Imaging proteins in vivo using fluorescence lifetime microscopy. Mol. Biosyst. 3, 381-391 (2007).

29. M. T. Kelleher, G. Fruhwirth, G. Patel, E. Ofo, F. Festy, P. R. Barber, S. M. Ameer-Beg B. Vojnovic, C. Gillett, A. Coolen, G. Kéri, P. A. Ellis, T. Ng, The potential of optical proteomic technologies to individualize prognosis and guide rational treatment for cancer patients. Target Oncol. 4, 235-252 (2009).

30. G. O. Fruhwirth, L. P. Fernandes, G. Weitsman, G. Patel, M. Kelleher, K. Lawler, A. Brock S. P. Poland, D. R. Matthews, G. Kéri, P. R. Barber, B. Vojnovic, S. M. Ameer-Beg, A. C. Coolen, F. Fraternali, T. Ng, How Förster resonance energy transfer imaging improves the understanding of protein interaction networks in cancer biology. Chemphyschem 12, 442-461 (2011).

31. B. Treanor, P. M. Lanigan, S. Kumar, C. Dunsby, I. Munro, E. Auksorius, F. J. Culley, M. A. Purbhoo, D. Phillips, M. A. Neil, D. N. Burshtyn, P. M. French, D. M. Davis Microclusters of inhibitory killer immunoglobulin-like receptor signaling at natural kille cell immunological synapses. J. Cell Biol. 174, 153-161 (2006).

32. T. N. Sims, T. J. Soos, H. S. Xenias, B. Dubin-Thaler, J. M. Hofman, J. C. Waite, T. O. Cameron, V. K. Thomas, R. Varma, C. H. Wiggins, M. P. Sheetz, D. R. Littman M. L. Dustin, Opposing effects of PKC $\theta$ and WASp on symmetry breaking and relocation of the immunological synapse. Cell 129, 773-785 (2007).

33. T. S. Keshava Prasad, R. Goel, K. Kandasamy, S. Keerthikumar, S. Kumar, S. Mathivanan, D. Telikicherla, R. Raju, B. Shafreen, A. Venugopal, L. Balakrishnan, A. Marimuthu, S. Banerjee, D. S. Somanathan, A. Sebastian, S. Rani, S. Ray, C. J. Harrys Kishore, S. Kanth, M. Ahmed, M. K. Kashyap, R. Mohmood, Y. L. Ramachandra, V. Krishna, B. A Rahiman, S. Mohan, P. Ranganathan, S. Ramabadran, R. Chaerkady, A. Pandey, Human Protein Reference Database-2009 update. Nucleic Acids Res. 37, D767-D772 (2009).

34. R. D. Finn, J. Tate, J. Mistry, P. C. Coggill, S. J. Sammut, H. R. Hotz, G. Ceric, K. Forslund, S. R. Eddy, E. L. Sonnhammer, A. Bateman, The Pfam protein families database. Nucleic Acids Res. 36, D281-D288 (2008).
35. N. K. Hussain, S. Jenna, M. Glogauer, C. C. Quinn, S. Wasiak, M. Guipponi, S. E. Antonarakis, B. K. Kay, T. P. Stossel, N. Lamarche-Vane, P. S. McPherson, Endocytic protein intersectin-I regulates actin assembly via Cdc42 and N-WASP. Nat. Cell Biol. 3 , 927-932 (2001)

36. L. Wang, K. Zhu, Y. Zheng, Oncogenic Dbl, Cdc42, and p21-activated kinase form a ternary signaling intermediate through the minimum interactive domains. Biochemistry 43, 14584-14593 (2004).

37. I. Bose, J. E. Irazoqui, J. J. Moskow, E. S. Bardes, T. R. Zyla, D. J. Lew, Assembly of scaffold-mediated complexes containing Cdc42p, the exchange factor Cdc24p, and the effector Cla4p required for cell cycle-regulated phosphorylation of Cdc24p. J. Biol. Chem. 276, 7176-7186 (2001)

38. L. Ardouin, M. Bracke, A. Mathiot, S. N. Pagakis, T. Norton, N. Hogg, V. L. Tybulewicz, Vav1 transduces TCR signals required for LFA-1 function and cell polarization at the immunological synapse. Eur. J. Immunol. 33, 790-797 (2003).

39. M. A. del Pozo, M. A. Schwartz, J. Hu, W. B. Kiosses, A. Altman, M. Villalba, Guanine exchange-dependent and -independent effects of Vav1 on integrin-induced $\mathrm{T}$ cell spreading. J. Immunol. 170, 41-47 (2003)

40. L. I. Salazar-Fontana, V. Barr, L. E. Samelson, B. E. Bierer, CD28 engagement promotes actin polymerization through the activation of the small Rho GTPase Cdc42 in human T cells. J. Immunol. 171, 2225-2232 (2003).

41. D. B. Graham, M. Cella, E. Giurisato, K. Fujikawa, A. V. Miletic, T. Kloeppel, K. Brim T. Takai, A. S. Shaw, M. Colonna, W. Swat, Vav1 controls DAP10-mediated natural cytotoxicity by regulating actin and microtubule dynamics. J. Immunol. 177, 23492355 (2006).

42. S. Mesecke, D. Urlaub, H. Busch, R. Eils, C. Watzl, Integration of activating and inhibitory receptor signaling by regulated phosphorylation of Vav1 in immune cells. Sci. Signal. 4, ra36 (2011).

43. O. D. Perez, D. Mitchell, G. C. Jager, G. P. Nolan, LFA-1 signaling through p44/42 is coupled to perforin degranulation in $\mathrm{CD}^{+} 6^{+} \mathrm{CD}^{+}$natural killer cells. Blood 104, 1083-1093 (2004)

44. I. Dransfield, C. Cabañas, J. Barrett, N. Hogg, Interaction of leukocyte integrins with ligand is necessary but not sufficient for function. J. Cell Biol. 116, 1527-1535 (1992).

45. Z. Li, M. Hannigan, Z. Mo, B. Liu, W. Lu, Y. Wu, A. V. Smrcka, G. Wu, L. Li, M. Liu, C. K. Huang, D. Wu, Directional sensing requires G $\beta \gamma$-mediated PAK1 and PIX $\alpha$ dependent activation of Cdc42. Cell 114, 215-227 (2003).

46. D. Baird, Q. Feng, R. A. Cerione, The Cool-2/ $\alpha$-Pix protein mediates a Cdc42-Rac signaling cascade. Curr. Biol. 15, 1-10 (2005)

47. A. Simmons, B. Gangadharan, A. Hodges, K. Sharrocks, S. Prabhakar, A. García R. Dwek, N. Zitzmann, A. McMichael, Nef-mediated lipid raft exclusion of UbcH7 inhibits $\mathrm{Cbl}$ activity in T cells to positively regulate signaling. Immunity 23, 621-634 (2005).

48. J. A. Escobedo, S. Navankasattusas, W. M. Kavanaugh, D. Milfay, V. A. Fried, L. T. Williams, cDNA cloning of a novel $85 \mathrm{kd}$ protein that has $\mathrm{SH} 2$ domains and regulates binding of PI3-kinase to the PDGF $\beta$-receptor. Cell 65, 75-82 (1991).

49. V. Stoll, V. Calleja, G. Vassaux, J. Downward, N. R. Lemoine, Dominant negative inhibitors of signalling through the phosphoinositol 3-kinase pathway for gene therapy of pancreatic cancer. Gut 54, 109-116 (2005).

50. O. Carpen, I. Virtanen, E. Saksela, Ultrastructure of human natural killer cells: Nature of the cytolytic contacts in relation to cellular secretion. J. Immunol. 128, 2691-2697 (1982)

51. J. S. Orange, K. E. Harris, M. M. Andzelm, M. M. Valter, R. S. Geha, J. L. Strominger, The mature activating natural killer cell immunologic synapse is formed in distinct stages. Proc. Natl. Acad. Sci. U.S.A. 100, 14151-14156 (2003).

52. S. Etienne-Manneville, A. Hall, Integrin-mediated activation of Cdc42 controls cell polarity in migrating astrocytes through PKC $\zeta$. Cell 106, 489-498 (2001).

53. C. Wülfing, M. M. Davis, A receptor/cytoskeletal movement triggered by costimulation during T cell activation. Science 282, 2266-2269 (1998)

54. L. J. Standeven, L. M. Carlin, P. Borszcz, D. M. Davis, D. N. Burshtyn, The actin cytoskeleton controls the efficiency of killer Ig-like receptor accumulation at inhibitory NK cell immune synapses. J. Immunol. 173, 5617-5625 (2004).

55. R. S. Flannagan, R. E. Harrison, C. M. Yip, K. Jaqaman, S. Grinstein, Dynamic macrophage "probing" is required for the efficient capture of phagocytic targets. J. Cell Biol. 191, 1205-1218 (2010).

56. A. I. Su, T. Wiltshire, S. Batalov, H. Lapp, K. A. Ching, D. Block, J. Zhang, R. Soden, M. Hayakawa, G. Kreiman, M. P. Cooke, J. R. Walker, J. B. Hogenesch, A gene atlas of the mouse and human protein-encoding transcriptomes. Proc. Natl. Acad. Sci. U.S.A 101, 6062-6067 (2004)

57. C. Wu, C. Orozco, J. Boyer, M. Leglise, J. Goodale, S. Batalov, C. L. Hodge, J. Haase J. Janes, J. W. Huss III, A. I. Su, BioGPS: An extensible and customizable portal for querying and organizing gene annotation resources. Genome Biol. 10, R130 (2009).

58. K. Aoki, T. Nakamura, K. Fujikawa, M. Matsuda, Local phosphatidylinositol 3,4,5trisphosphate accumulation recruits Vav2 and Vav3 to activate Rac1/Cdc42 and initiate neurite outgrowth in nerve growth factor-stimulated PC12 cells. Mol. Biol. Cell 16, 2207-2217 (2005). 
59. A. Awasthi, A. Samarakoon, X. Dai, R. Wen, D. Wang, S. Malarkannan, Deletion of $\mathrm{PI} 3 \mathrm{~K}-\mathrm{p} 85 \alpha$ gene impairs lineage commitment, terminal maturation, cytokine generation and cytotoxicity of NK cells. Genes Immun. 9, 522-535 (2008).

60. C. M. Segovis, R. A. Schoon, C. J. Dick, L. P. Nacusi, P. J. Leibson, D. D. Billadeau, PI3K links NKG2D signaling to a CrkL pathway involved in natural killer cell adhesion, polarity, and granule secretion. J. Immunol. 182, 6933-6942 (2009).

61. C. Li, B. Ge, M. Nicotra, J. N. Stern, H. D. Kopcow, X. Chen, J. L. Strominger, JNK MAP kinase activation is required for MTOC and granule polarization in NKG2Dmediated NK cell cytotoxicity. Proc. Natl. Acad. Sci. U.S.A. 105, 3017-3022 (2008)

62. M. Cella, K. Fujikawa, I. Tassi, S. Kim, K. Latinis, S. Nishi, W. Yokoyama, M. Colonna W. Swat, Differential requirements for Vav proteins in DAP10- and ITAM-mediated NK cell cytotoxicity. J. Exp. Med. 200, 817-823 (2004).

63. A. Di Cesare, S. Paris, C. Albertinazzi, S. Dariozzi, J. Andersen, M. Mann, R. Longhi, I. de Curtis, p95-APP1 links membrane transport to Rac-mediated reorganization of actin. Nat. Cell Biol. 2, 521-530 (2000).

64. K. T. Hua, C. T. Tan, G. Johansson, J. M. Lee, P. W. Yang, H. Y. Lu, C. K. Chen, J. L. Su, P. B. Chen, Y. L. Wu, C. C. Chi, H. J. Kao, H. J. Shih, M. W. Chen, M. H. Chien, P. S. Chen W. J. Lee, T. Y. Cheng, G. Rosenberger, C. Y. Chai, C. J. Yang, M. S. Huang, T. C. Lai, T. Y. Chou, M. Hsiao, M. L. Kuo, $N$ - $\alpha$-Acetyltransferase 10 protein suppresses cancer cell metastasis by binding PIX proteins and inhibiting Cdc42/Rac1 activity. Cancer Cell 19, 218-231 (2011)

65. G. M. Ku, D. Yablonski, E. Manser, L. Lim, A. Weiss, A PAK1-PIX-PKL complex is activated by the T-cell receptor independent of Nck, Slp-76 and LAT. EMBO J. 20 , 457-465 (2001).

66. J. Zhang, J. Zhu, X. Bu, M. Cushion, T. B. Kinane, H. Avraham, H. Koziel, Cdc42 and RhoB activation are required for mannose receptor-mediated phagocytosis by human alveolar macrophages. Mol. Biol. Cell 16, 824-834 (2005).

67. D. Khurana, P. J. Leibson, Regulation of lymphocyte-mediated killing by GTP-binding proteins. J. Leukoc. Biol. 73, 333-338 (2003).

68. D. E. Nelson, A. E. Ihekwaba, M. Elliott, J. R. Johnson, C. A. Gibney, B. E. Foreman, G. Nelson, V. See, C. A. Horton, D. G. Spiller, S. W. Edwards, H. P. McDowell, J. F. Unitt, E. Sullivan, R. Grimley, N. Benson, D. Broomhead, D. B. Kell, M. R. White, Oscillations in NF-kB signaling control the dynamics of gene expression. Science 306, 704-708 (2004).

69. L. Ashall, C. A. Horton, D. E. Nelson, P. Paszek, C. V. Harper, K. Sillitoe, S. Ryan, D. G. Spiller, J. F. Unitt, D. S. Broomhead, D. B. Kell, D. A. Rand, V. See, M. R. White Pulsatile stimulation determines timing and specificity of NF-KB-dependent transcription. Science 324, 242-246 (2009).

70. S. Dai, Y. Zhang, T. Weimbs, M. B. Yaffe, D. Zhou, Bacteria-generated Ptdlns(3) $P$ recruits VAMP8 to facilitate phagocytosis. Traffic 8, 1365-1374 (2007).

71. J. Yodoi, K. Teshigawara, T. Nikaido, K. Fukui, T. Noma, T. Honjo, M. Takigawa, M. Sasaki, N. Minato, M. Tsudo, TCGF (IL 2)-receptor inducing factor(s). I. Regulation of IL 2 receptor on a natural killer-like cell line (YT cells). J. Immunol. 134, 1623-1630 (1985).

72. Y. Shimizu, D. E. Geraghty, B. H. Koller, H. T. Orr, R. DeMars, Transfer and expression of three cloned human non-HLA-A,B,C class I major histocompatibility complex genes in mutant lymphoblastoid cells. Proc. Natl. Acad. Sci. U.S.A. 85, 227-231 (1988)
73. L. M. Carlin, K. Eleme, F. E. McCann, D. M. Davis, Intercellular transfer and supramolecular organization of human leukocyte antigen $\mathrm{C}$ at inhibitory natural killer cell immune synapses. J. Exp. Med. 194, 1507-1517 (2001)

74. M. Peter, S. M. Ameer-Beg, M. K. Hughes, M. D. Keppler, S. Prag, M. Marsh, B. Vojnovic, T. Ng, Multiphoton-FLIM quantification of the EGFP-mRFP1 FRET pair for localization of membrane receptor-kinase interactions. Biophys. J. 88, 1224-1237 (2005).

75. W. S. Rasband, ImageJ (U.S. National Institutes of Health, Bethesda, MD, 1997-2009).

76. K. Livak, ABI Prism 7700 Sequence Detection System. User Bulletin 2 (PE Applied Biosystems, Foster City, CA, 1997).

Acknowledgments: We thank N. Hogg [Cancer Research UK (CRUK), London Research Institute] for her gift of mAb TS2/4. We are grateful to A. Ridley [King's College London (KCL)] and D. Bar-Sagi (New York University School of Medicine) for reviewing this manuscript and for their insightful comments. Funding: This work was supported by CRUK Programme grant C133/A/1812 (to P.R.B. and B.V.); UK Engineering and Physical Sciences Research Council (EPSRC) grant EP/C546105/1 (to L.M.C.); Wellcome Trust Value in People award 087819/Z/08/Z (to L.M.C.); the KCL-University College London Comprehensive Cancer Imaging Centre (KCL-UCL CCIC), funded by CRUK and EPSRC, in association with the Medical Research Council and Department of Health (England) (to R.E.); the National Institute for Health Research Comprehensive Biomedical Research Centre award to Guy's and St Thomas' National Health Service (NHS) Foundation Trust in partnership with KCL and King's College Hospital NHS Foundation Trust C1519/A10331 (to R.E.); Leukaemia and Lymphoma Research grant (07066, to N.S.B.T.); Biotechnology and Biological Sciences Research Council Programme grant BB/G007160/1 (to D.R.M. and M.P.); KCL Breakthrough Breast Cancer Research Unit funding (to J.M.); and an endowment fund from Dimbleby Cancer Care to KCL (to S.A.-B. and T.N.). The FLIM system was built with support from the Medical Research Council Co-operative Group grant (G0100152 ID 56891), a UK Research Councils Basic Technology Research Programme grant (GR/R87901/01), and the KCL-UCL CCIC. Author contributions: L.M.C., R.E., H.M., L.F., D.R.M., J.L., and J.M. performed and designed experiments; M.P., M.D.K., T.C., P.R.B., B.V., K.S., F.F., S.A.-B., P.J.P., and N.S.B.T. provided reagents and analytical tools and participated in the design of the study and interpretation of the results; L.M.C., R.E., H.M., L.F., F.F., and T.N. analyzed and interpreted results; and L.M.C., R.E., F.F., L.F., and T.N. designed the research and wrote the paper. Competing interests: The authors declare that they have no competing interests.

Submitted 1 December 2010

Accepted 9 November 2011

Final Publication 29 November 2011

10.1126/scisignal.2001729

Citation: L. M. Carlin, R. Evans, H. Milewicz, L. Fernandes, D. R. Matthews, M. Perani, J. Levitt, M. D. Keppler, J. Monypenny, T. Coolen, P. R. Barber, B. Vojnovic, K. Suhling, F. Fraternali, S. Ameer-Beg, P. J. Parker, N. S. B. Thomas, T. Ng, A targeted siRNA screen identifies regulators of $\mathrm{Cdc42}$ activity at the natural killer cell immunological synapse. Sci. Signal. 4, ra81 (2011). 